\title{
The Effect of Deviations from Pseudo First-Order Conditions on Transient Electrochemical Response as Illustrated by the Protonation of Anthracene Anion Radical by Phenol in $\mathbf{N}, \mathbf{N}$ - Dimethylformamide
}

\author{
Merete Folmer Nielsen, ${ }^{a}$ Ole Hammerich ${ }^{a}$ and Vernon D. Parker ${ }^{b}$ \\ a Department of General and Organic Chemistry, The H.C. Ørsted Institute, University of Copenhagen, \\ Universitetsparken 5, DK-2100 Copenhagen, Denmark and ' ${ }^{\mathrm{L}}$ aboratory for Organic Chemistry, Norwegian \\ Institute of Technology, University of Trondheim, N-7034 Trondheim-NTH, Norway
}

Nielsen, M. F., Hammerich, O. and Parker, V. D., 1987. The Effect of Deviations from Pseudo First-Order Conditions on Transient Electrochemical Response as Illustrated by the Protonation of Anthracene Anion Radical by Phenol in $N, N$-Dimethylformamide. - Acta Chem. Scand. B 41: 50-63.

Experimental data obtained by derivative cyclic voltammetry (DCV) and double potential step chronoamperometry (DPSC) for the protonation of anthracene anion radical $\left(\mathrm{A}^{-}\right)$by phenol $(\mathrm{PhOH})$ in $N, N$-dimethylformamide have resulted in apparently contradictory reaction orders with respect to $\mathrm{PhOH}, \sim 1.2$ by DCV and $\sim 1.0$ by DPSC, at values of $C_{\mathrm{PhOH}}^{\circ} / C_{\mathrm{A}}^{\circ}$ which were believed to be under pseudo first-order conditions. However, theoretical data for the reaction scheme (1)-(5), the rate law for which is strictly first-order in $\mathrm{PhOH}$ [eqn. (6)], have demonstrated that the assumption of pseudo first-order conditions breaks down when $C_{\mathrm{PhOH}}^{\circ} / C_{\mathrm{A}}^{\circ}$ is smaller than approximately $\sim 25$ (DCV) and $\sim 5$ (DPSC).

$\mathrm{A}+\mathrm{e}^{-} \rightleftharpoons \mathrm{A}$

$\mathrm{A}^{-}+\mathrm{PhOH} \stackrel{k_{2}}{\longrightarrow} \mathrm{AH}^{\cdot}+\mathrm{PhO}^{-}$

$\mathrm{AH}+\mathrm{A}^{-} \rightarrow \mathrm{AH}^{-}+\mathrm{A}$

$\mathrm{AH}^{-}+\mathrm{PhOH} \rightarrow \mathrm{AH}_{2}+\mathrm{PhO}^{-}$

$\mathrm{PhOH}+\mathrm{PhO}^{-} \rightarrow \mathrm{PhOH} / \mathrm{PhO}^{-}$

$-\mathrm{d}\left[\mathrm{A}^{-}\right] / \mathrm{d} t=2 k_{2}\left[\mathrm{~A}^{-}\right][\mathrm{PhOH}]$

Above these values, the error in $k_{2}$ is less than $5 \%$. The difference in the sensitivity of the two techniques to the magnitude of $C_{\mathrm{PhOH}}^{\circ} / C_{\mathrm{A}}^{\circ}$ is related to the fact that the material conversion during DCV is higher than during DPSC. Reaction order analysis of the theoretical data in the region $C_{\mathrm{PhOH}}^{\circ} / C_{\mathrm{A}}^{\circ}=6-100$ resulted in the values 1.07 (DCV) and 1.01 (DPSC). The deviation of the DCV value from unity is further accentuated when the diffusion coefficient ratio, $D_{\mathrm{A}} / D_{\mathrm{PhOH}}$, is allowed to increase, whereas the DPSC value was essentially insensitive to the magnitude of this parameter. The difference between the experimental reaction order, $\sim 1.2$, and the theoretical, 1.07, is suggested to reflect contributions from the dimer $(\mathrm{PhOH})_{2}$ as proton donor at high values of $C_{\mathrm{PhOH}}^{\circ}$. Experimental DCV data obtained at $C_{\mathrm{PhOH}}^{\circ} / C_{\mathrm{A}}^{\circ}=1$ and 2 provided support for the view that formation of the $\mathrm{PhOH} / \mathrm{PhO}^{-}$complex [reaction (5)] may be regarded as an irreversible process under the experimental conditions. 
The study of the formation and chemical reactions of anion radicals derived from organic compounds has developed into a major research area in mechanistic organic chemistry. This is reflected by the steadily increasing number of organic reactions for which new experimental data have forced the discussions of mechanisms to include anion radicals as key intermediates. ${ }^{1-5}$ Due to the strongly basic properties of most anion radicals, studies of their formation and reactions, including kinetic and synthetic aspects, have most frequently been carried out in aprotic solvents like acetonitrile $(\mathrm{MeCN}), N, N$-dimethylformamide (DMF), dimethyl sulfoxide (DMSO) and hexamethylphosphoric triamide (HMPT), as well as tetrahydrofuran (THF) and related aliphatic ethers. ${ }^{1-8}$ Common to all these solvents is a poor ability to solvate anions. ${ }^{9}$ As a well-known consequence of this, anion radicals form ion pairs with cations and this complicates the interpretation of kinetic data, as demonstrated by a series of studies of the protonation of anthracene anion radical in ethers. ${ }^{10-14} \mathrm{~A}$ problem related to the formation of ion pairs is whether the conjugate bases of the proton donors formed during the protonation of anion radicals exist as free anions or are specifically associated with other solution components. The importance of this aspect of mechanistic studies of anion radical reactions may be illustrated by the protonation of anthracene anion radical $\left(\mathrm{A}^{-}\right)$by phenol $(\mathrm{PhOH})$ in DMF. The study of this reaction by electroanalytical techniques has been hampered by a number of apparent inconsistencies which have resulted in controversy, both regarding the experimental results and their mechanistic interpretation. ${ }^{15-22}$ With respect to the application of linear sweep voltammetry (LSV), we have recently demonstrated $^{23}$ that a major cause of the discrepancies has been the assumption of an incorrect stoichiometry in the theoretical treatment of the reaction pathway, which, in addition to the steps discussed in the earlier work (eqns. $1-4),{ }^{15-22}$ features the essentially irreversible formation of a complex between $\mathrm{PhO}^{-}$and $\mathrm{PhOH}$ (eqn. 5). The fact that $\mathrm{PhO}^{-}$ions in aprotic solvents containing an excess of $\mathrm{PhOH}$ do not exist as the free anions, but almost exclusively as the $\mathrm{PhOH} /$ $\mathrm{PhO}^{-}$complex, ${ }^{24-30}$ has the consequence that four molecules of $\mathrm{PhOH}$ instead of two are consumed for each two molecules of $\mathrm{A}^{-}$reacting, as shown by the stoichiometric eqn. (6). The importance of this point for the analysis of the experimental LSV data has already been discussed in detail in our previous paper ${ }^{23}$, in which the interested reader may also find a full account of the previous work based on the LSV technique.

$\mathrm{A}+\mathrm{e}^{-} \rightleftharpoons \mathrm{A}^{-}$

$\mathrm{A}^{-}+\mathrm{PhOH} \stackrel{k_{2}}{\longrightarrow} \mathrm{AH}^{\cdot}+\mathrm{PhO}^{-}$

$\mathrm{AH}^{\cdot}+\mathrm{A}^{=} \underset{\text { fast }}{\stackrel{k_{3}}{\longrightarrow}} \mathrm{AH}^{-}+\mathrm{A}$

$\mathrm{AH}^{-}+\mathrm{PhOH} \underset{\text { fast }}{\stackrel{k_{4}}{\longrightarrow}} \mathrm{AH}_{2}+\mathrm{PhO}^{-}$

$\mathrm{PhOH}+\mathrm{PhO}^{-} \stackrel{K_{5}}{\rightleftharpoons} \mathrm{PhOH} / \mathrm{PhO}^{-}\left(K_{5} \gg 1\right)$

$2 \mathrm{~A}^{\mp}+4 \mathrm{PhOH} \rightarrow \mathrm{AH}_{2}+\mathrm{A}+2 \mathrm{PhOH} / \mathrm{PhO}^{-}$

Here we give only a brief summary together with a review of the earlier results obtained by double potential step chronoamperometry (DPSC) and derivative cyclic voltammetry (DCV) which are relevant to our new data and the discussion to follow. Throughout the paper, the symbol $C_{\mathrm{X}}^{\circ}$ is used for the stoichiometric concentration and [X] for the actual concentration of species $\mathrm{X}$ in solution.

The aim of the first DPSC study of the reaction $^{15}$ was to determine whether the second electron transfer following the protonation of $\mathrm{A}^{\text {}}$ occurred predominantly at the electrode or took place in solution ${ }^{31}$ via $\mathrm{A}^{-}$(eqn. 3). The experimental data from measurements on a solution with $C_{\mathrm{A}}^{\circ}=1 \mathrm{mM}$ and $C_{\mathrm{PhOH}}^{\circ}=10 \mathrm{mM}$ gave a good fit to the working curve calculated for mechanism (1)-(4) assuming pseudo first-order conditions and rate-determining proton transfer (eqn.2). The corresponding pseudo first-order rate constant was observed to be $45 \mathrm{~s}^{-1}$, resulting in a value of $k_{2}$ of $4500 \mathrm{M}^{-1} \mathrm{~s}^{-1}$. It was pointed out that this value may seem surprisingly low for an exergonic proton-transfer reaction, but not if it is considered that protonation takes place at a carbon site. A value close to this, $4000 \mathrm{M}^{-1} \mathrm{~s}^{-1}$, was determined later by the same technique. ${ }^{17}$

Since the mechanism appeared to be well es- 
tablished, the protonation of $\mathrm{A}^{-}$by $\mathrm{PhOH}$ in DMF was chosen as a reference system against which the newly developed DCV technique could be tested. ${ }^{17,18}$ The mechanism assignment appeared to be supported by the data obtained by DCV, but a slight increase in the resulting rate constant with increasing $C_{\mathrm{PhOH}}^{\circ}$ was observed. ${ }^{17} \mathrm{At}$ the time of publication, this observation was thought to reflect contributions from discharge of protons at the highest $\mathrm{PhOH}$ concentrations. The average value of $k_{2}$ resulting from the DCV measurements was found to be $5300 \mathrm{M}^{-1} \mathrm{~s}^{-1}$, in fair agreement with the values determined by DPSC. However, more detailed work on the mechanism ${ }^{19,20}$ provided experimental LSV and DCV data incompatible with a scheme including only (1) and the irreversible steps (2)-(4) with (2) being rate-determining. Although the reaction appeared to be of first-order both in $\mathrm{A}^{-}$and $\mathrm{PhOH}$ at high $\mathrm{PhOH}$ concentrations $\left(C_{\mathrm{PhOH}}^{\circ}=40\right.$ $\left.100 \mathrm{mM} ; C_{\mathrm{A}}^{\circ}=1 \mathrm{mM}\right)$, the experimental data indicated reaction orders significantly higher than unity at low $\mathrm{PhOH}$ concentrations $\left(C_{\mathrm{PhOH}}^{\mathrm{O}}=\right.$ 10-20 mM; $C_{\mathrm{A}}^{\circ}=1 \mathrm{mM}$ ). This, together with the observation that the reaction was inhibited by addition of $\mathrm{PhO}^{-}$ion, led to the proposal of a transition from the simple mechanism with rate determining protonation of $\mathrm{A}^{-}$(eqn. 2) at high $\mathrm{PhOH}$ concentrations to a more complex scheme incorporating back reactions (2) and (3) at low $\mathrm{PhOH}$ concentrations.

This mechanism transition was sharply criticized on the basis of a kinetic zone diagram analysis ${ }^{21}$ and it was emphasized that the limiting case including the reversible steps (2) and (3) followed by rate-determining protonation of $\mathrm{AH}^{-}$ (eqn. 4) requires an unacceptably low value of $k_{4}$ for the homogeneous electron-transfer reaction (3) to remain at equilibrium. With an estimated difference between $E_{\mathrm{AA}=}^{\circ}$ and $E_{\mathrm{AH} / \mathrm{AH}}^{\circ}$ of at least $600 \mathrm{mV}$, the value of the equilibrium constant $K_{3}$ was suggested to be larger than $10^{10}$ which, together with the assumption that forward step (3) proceeds at the diffusion controlled rate, led to a maximum value of $2 \mathrm{M}^{-1} \mathrm{~s}^{-1}$ for $k_{4}$. On the other hand, $\mathrm{AH}^{-}$is expected to be a much stronger base than $\mathrm{A}^{\mp}$ and $k_{4}$ would for this reason be expected to be considerably larger than $k_{2}$, i.e. than $\sim 4500 \mathrm{M}^{-1} \mathrm{~s}^{-1}$. This estimate of $k_{4}$ based on chemical reasoning is approximately three orders of magnitude higher than the maximum value required by the mechanism including the reversible steps (2) and (3) and rate-determining step (4), and for this reason this mechanism was deemed improbable. Comparison of DPSC data with working curves for two other limiting mechanisms, one with the electrode reaction $\mathrm{AH}^{\cdot}+\mathrm{e}^{-}$ $\rightarrow \mathrm{AH}^{-}$replacing (3) and another including the reversible reaction (2) followed by rate-determining (3), demonstrated that neither of these could account satisfactorily for the experimental results. The data appeared to give a good fit only to the working curve for mechanism (1)-(4) with rate-determining (2) and it was concluded that protonation of $\mathrm{A}^{-}$by $\mathrm{PhOH}$ in the concentration ranges $C_{\mathrm{A}}^{\circ}=0.5-2 \mathrm{mM}$ and $C_{\mathrm{PhOH}}^{\circ}=10-100 \mathrm{mM}$ is consistent with that mechanism, with no appreciable contribution of the other possible limiting mechanisms.

However, new LSV results and re-analysis of old data reopened the discussion. ${ }^{22}$ Values of $\mathrm{d} E_{\mathrm{p}} /$ $\operatorname{d} \log C_{\mathrm{PhOH}}^{\circ}$ were demonstrated in general to be larger than the $29.1 \mathrm{mV}$ required by a simple reaction first-order in $\mathrm{PhOH}$ and, as a consequence of this, a new and more complicated mechanism including the steps (1), (7)-(10) and rate law (11) was suggested. ${ }^{22}$ The essential feature of this mechanism was the formation of $1: 1$ and $1: 2 \mathrm{com}-$ plexes between $\mathrm{A}^{\overline{ }}$ and $\mathrm{PhOH}$. Depending on the competition between steps $(8)$ and $(9,10)$, this mechanism will give reaction orders with respect to $\mathrm{PhOH}$ of between one and two and, accordingly, $\mathrm{d} E_{\mathrm{p}} / \mathrm{d} \log C_{\mathrm{PhOH}}^{\circ}$ values between $29.1 \mathrm{mV}$ and $58.2 \mathrm{mV}$. Incorporation of these complexes in the theoretical DPSC treatment resulted in a working curve which seemed to fit the experimental data even better than that for the simple mechanism, and this was taken as supporting evidence for the new mechanism proposal.

$$
\mathrm{A}+\mathrm{e}^{-} \rightleftharpoons \mathrm{A}^{-}
$$

$\mathrm{A}^{\mp}+\mathrm{PhOH} \stackrel{K_{7}}{\rightleftharpoons} \mathrm{A}^{\mp} / \mathrm{PhOH}$

$\mathrm{A}^{\top} / \mathrm{PhOH} \stackrel{k_{8}}{=} \mathrm{AH}^{\cdot}+\mathrm{PhO}^{-}$

$\mathrm{A}^{\mp} / \mathrm{PhOH}+\mathrm{PhOH} \stackrel{K_{9}}{=} \mathrm{A}^{\mp} / 2 \mathrm{PhOH}$

$$
\begin{aligned}
\mathrm{A}^{\mp} / 2 \mathrm{PhOH} \stackrel{k_{10}}{=} & \mathrm{AH}^{\cdot}+\mathrm{PhOH}+\mathrm{PhO}^{-} \\
-\mathrm{d}\left[\mathrm{A}^{\mp}\right] / \mathrm{d} t= & k_{8} K_{7}\left[\mathrm{~A}^{\mp}\right][\mathrm{PhOH}] \cdot \\
& \left(1+\left(k_{10} / k_{8}\right) K_{9}[\mathrm{PhOH}]\right)
\end{aligned}
$$


During the earlier work, the experimental conditions typically included stoichiometric concentrations of anthracene and phenol, $C_{\mathrm{A}}^{\circ}$ and $C_{\mathrm{PhOH}}^{\circ}$, equal to $1 \mathrm{mM}$ and $10-100 \mathrm{mM}$, respectively. The data treatment was carried out under two basic assumptions: (i) that this excess of $\mathrm{PhOH}$ is sufficiently large to allow the reaction to be treated kinetically as a pseudo first-order process and (ii) that the reaction is fast enough compared to the LSV sweep rate, $v$, to be under purely kinetic control. With regard to LSV we have demonstrated $^{23}$ that neither of the two assumptions are valid in the entire concentration and sweep rate ranges of the earlier studies. Furthermore, the theoretical analysis showed that the observed values of $\mathrm{d} E_{\mathrm{p}} / \mathrm{d} \log v$ and $\mathrm{d} E_{\mathrm{p}} / \mathrm{d} \log C_{\mathrm{PhOH}}^{\circ}$ are in good agreement with the simple sequence (1)-(4) when the reaction rate and the stoichiometric consequences of the formation of the $\mathrm{PhOH} /$ $\mathrm{PhO}^{-}$complex (5) are taken into account. The addition of step (5) to the original scheme, (1)-(4), also accounts for the inhibition of $\mathrm{PhO}^{-}$ ion. Due to the essentially irreversible formation of the $\mathrm{PhOH} / \mathrm{PhO}^{-}$complex, a given amount of $\mathrm{PhO}^{-}$added to the voltammetric solution will consume an equivalent amount of $\mathrm{PhOH}$, resulting in a reduction in the concentration of free $\mathrm{PhOH}$ and accordingly in the rate of step (2).

Focusing now only on the application of the transient electrochemical techniques, DPSC and $\mathrm{DCV}$, the question of whether the reaction is under purely kinetic control is obviously no longer relevant, since we are dealing with techniques which operate on a time scale comparable with that of the $\mathrm{A}^{-}$half-life. However, the consequences of deviations from pseudo first-order conditions at low values of $C_{\mathrm{PhOH}}^{\circ} / C_{\mathrm{A}}^{\circ}$, enhanced by the formation of $\mathrm{PhOH} / \mathrm{PhO}^{-}$, remain to be clarified. That is the subject of this paper.

\section{Results and discussion}

Before going into the presentation and discussion of the new DPSC and DCV data, it is pertinent to comment on how reaction orders are related to experimental results. The straightforward translation of electroanalytical data to reaction orders rests on the validity of several assumptions. Most important in the present context are (i) that the reaction mechanism does not depend on variations in the potential sweep rate or the concentration ratio, $C_{\mathrm{PhOH}}^{\circ} / C_{\mathrm{A}}^{\circ}$, (ii) that the reaction takes place under pseudo first-order conditions in the entire range of $C_{\mathrm{PhOH}}^{\circ} / C_{\mathrm{A}}^{\circ}$ values and (iii), for LSV only, that the reaction is under purely kinetic control. What is meant by the latter term is that the rate of the chemical process following the heterogeneous electron transfer step is fast compared to the potential sweep rate. ${ }^{32,33}$ This is generally expressed through the value of a dimensionless parameter, $k_{2} C_{\mathrm{PhOH}}^{\circ} R T /(v n F)$ for the present reaction under pseudo first-order conditions, which should be a large number. Under these conditions, the reaction orders referring to rate law (12) are related to the measurable electroanalytical parameters through the set of simple eqns. (13)-(19), ${ }^{34-36}$ in which $E_{\mathrm{p}}$ is the peak potential of the LSV wave, $v$ is the potential sweep rate and $\tau_{1 / 2}$ and $v_{1 / 2}$ are the DPSC pulse width and the DCV potential sweep rate necessary to keep the response ratios, $R_{\mathrm{I}}$ and $R_{\mathrm{I}}^{\prime}$, equal to 0.5 .

$$
\begin{aligned}
& -\mathrm{d}\left[\mathrm{A}^{\mp}\right] / \mathrm{d} t=k_{\mathrm{obs}}[\mathrm{A}]^{a}\left[\mathrm{~A}^{\mp}\right]^{b}[\mathrm{PhOH}]^{x} \\
& \mathrm{~d} E_{\mathrm{p}} / \mathrm{d} \log v=-\frac{1}{1+b} \frac{R T \ln 10}{n F} \\
& \mathrm{~d} E_{\mathrm{p}} / \mathrm{d} \log C_{\mathrm{A}}^{\circ}=\frac{a+b-1}{1+b} \frac{R T \ln 10}{n F} \\
& \mathrm{~d} E_{\mathrm{p}} / \mathrm{d} \log C_{\mathrm{PhOH}}^{\circ}=\frac{x}{1+b} \frac{R T \ln 10}{n F} \\
& \mathrm{~d} \log \left(1 / \tau_{1 / 2}\right) / \mathrm{d} \log C_{\mathrm{A}}^{\circ}=a+b-1 \\
& \mathrm{~d} \log \left(1 / \tau_{1 / 2}\right) / \mathrm{d} \log C_{\mathrm{PhOH}}^{\circ}=x \\
& \mathrm{~d} \log v_{1 / 2} / \mathrm{d} \log C_{\mathrm{A}}^{\circ}=a+b-1 \\
& \mathrm{~d} \log v_{1 / 2} / \mathrm{d} \log C_{\mathrm{PhOH}}^{\circ}=x
\end{aligned}
$$

For simple reaction mechanisms, the application of these reaction order equations involves the evaluation of slopes of linear regression lines. More complex mechanisms may give rise to curved plots and this curvature can be used to determine the nature of the complex mechanism. ${ }^{37,38}$ Similarly, in cases where the ratio $C_{\mathrm{PhOH}}^{\circ} / C_{\mathrm{A}}^{\circ}$ is not sufficiently large to ensure pseudo first-order conditions or when the value of $k_{2} C_{\mathrm{PhOH}}^{\circ} R T /(v n F)$ is not sufficiently large to govern purely kinetic conditions during LSV, the re- 
Table 1. The effect of the experimental conditions on the apparent reaction order with respect to $\mathrm{PhOH}$ determined by DPSC and DCV. ${ }^{a}$

\begin{tabular}{|c|c|c|c|c|c|}
\hline $\begin{array}{l}\text { Solvent } \\
\text { quality }\end{array}$ & Electrolyte & $\begin{array}{l}\text { Additional treatment } \\
\text { of the solvent/ } \\
\text { electrolyte system }\end{array}$ & Temp. $/{ }^{\circ} \mathrm{C}$ & $\frac{\mathrm{d} \log \left(1 / \tau_{1 / 2}\right)}{\mathrm{d} \log C_{\mathrm{PhOH}}^{\circ}}$ & $\frac{d \log v_{1 / 2}}{d \log C_{\mathrm{PhOH}}^{\circ}}$ \\
\hline Distd. & $\mathrm{Bu}_{4} \mathrm{NBF}_{4}{ }^{b}$ & None & 24 & 0.98 & 1.30 \\
\hline Not distd. & $\mathrm{Bu}_{4} \mathrm{NBF}_{4} c$ & Passed through $\mathrm{Al}_{2} \mathrm{O}_{3}{ }^{d}$ & 0 & 0.97 & 1.21 \\
\hline Distd. & $\mathrm{Bu}_{4} \mathrm{NBF}_{4}{ }^{b}$ & None & 0 & 0.98 & $-e$ \\
\hline Distd. & $\mathrm{Bu}_{4} \mathrm{NI}^{b}$ & None & 21 & $-{ }^{\theta}$ & 1.22 \\
\hline
\end{tabular}

${ }^{a}$ The solvent was DMF (Ferak) in all cases. $C_{\mathrm{A}}^{\circ}=1 \mathrm{mM}, C_{\mathrm{PhOH}}^{\circ}=10-100 \mathrm{mM}$ and $C_{\text {electrolye }}^{\circ}=0.1 \mathrm{M}$. ${ }^{\mathrm{b}} \mathrm{Fluka}$, purum. 'Prepared from $\mathrm{Bu}_{4} \mathrm{NHSO}_{4}$ and $\mathrm{HBF}_{4}$ as described in Ref. 23. ${ }^{d}$ Neutral (Woelm, W200). ${ }^{e}$ Not measured.

action order plots will reflect this. Under such conditions, the slopes of linear regression lines through the experimental points are not directly related to reaction orders through eqns. (13) $-(15)$, as previously discussed, ${ }^{2.3}$ or (16)-(19), as will become evident in what follows. For this reason, we will from now on refer to slopes of this kind as apparent reaction orders.

A major concern at the outset of the present investigation was the observation that DPSC data for the protonation of $\mathrm{A}^{-}$by $\mathrm{PhOH}$ apparently were in good agreement with a simple rate law first-order in $\mathrm{PhOH}$, whereas DCV data seemed to indicate a more complex rate law including a reaction order in $\mathrm{PhOH}$ higher than one; the question was raised whether this difference was real or an experimental artifact. To attempt to find the reason for this anomaly, a series of measurements using both techniques on the same solution were carried out in which the origin and the method of purification of the chemicals as well as the temperature were varied. The results are summarized in Table 1 and Fig. 1, and clearly show that the two techniques give a different message independent of the experimental conditions. The apparent reaction orders determined by DPSC were, without exception, unity within experimental error, whereas those determined by DCV were somewhat larger, the average of the data in Table 1 being 1.24. This value is in fair agreement with those resulting from the earlier studies, ${ }^{17.19}$ which amount to 1.10 and 1.33 when the experimental data are treated analogously.

In the report of one of these earlier DCV studies, ${ }^{17}$ it was suggested that the reason for the observation of a slightly increasing value of the ap- parent rate constant with increasing $\mathrm{PhOH}$ concentrations, i.e. of an apparent reaction order in $\mathrm{PhOH}$ higher than one, might be associated with contributions from discharge of protons, a parallel reaction which is expected to be of increasing importance with increasing $\mathrm{PhOH}$ concentration. If this is so, one would expect this to be a serious problem also in DPSC.

During DPSC measurements, the potential is

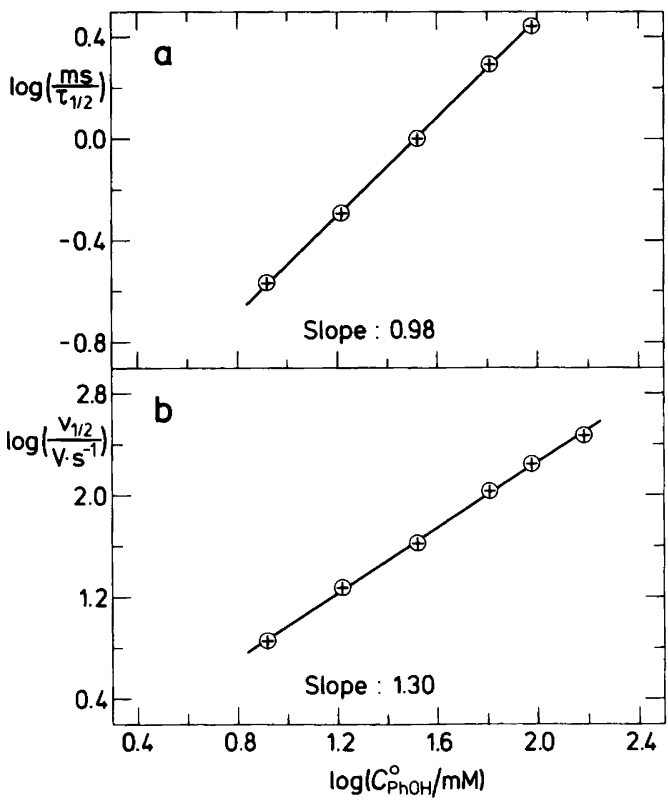

Fig. 1. Reaction order analysis by (a) DPSC and (b) $\mathrm{DCV}$ of the protonation of $\mathrm{A}^{-}$by $\mathrm{PhOH}$ in DMF. $C_{\mathrm{A}}^{\circ}=1 \mathrm{mM}, T=297 \mathrm{~K}$. 
Table 2. The effect of the switch potential, $E_{\mathrm{sw}}$, on DPSC reaction order analysis for the protonation of anthracene anion radical by phenol.

\begin{tabular}{llll}
\hline$E_{\mathrm{sw}}-E \% \mathrm{mV}$ & -200 & -300 & -400 \\
\hline$C_{\mathrm{PhOH}}^{\circ} / \mathrm{mM}$ & & $\tau_{1 / 2} / \mathrm{ms}$ \\
\cline { 1 - 4 } 10 & 3.48 & 3.55 & 3.55 \\
20 & 1.77 & 1.81 & 1.79 \\
40 & 0.89 & 0.92 & 0.92 \\
80 & 0.42 & 0.45 & 0.46 \\
$\frac{\mathrm{d} \log \left(1 / \tau_{1 / 2}\right)}{\mathrm{d} \log C_{\mathrm{PhOH}}^{\circ}}$ & 1.01 & 0.99 & 0.98 \\
\hline
\end{tabular}

stepped from a value at which no current flows to a value sufficiently negative to ensure that the heterogeneous electron transfer takes place at the diffusion-controlled rate. Typically, this involves a potential step to $E_{\mathrm{sw}}=E^{\circ}-300 \mathrm{mV}$. Obviously, the interference of proton reduction is expected to become increasingly important with numerically increasing values of $E_{\mathrm{sw}}$. Therefore, a series of experiments were carried out during which the magnitude of $E_{\mathrm{sw}}-E^{\circ}$ was changed between the values $-200,-300$ and $-400 \mathrm{mV}$. The results, which are summarized in Table 2 , showed that the apparent reaction order in $\mathrm{PhOH}$ is essentially independent of the difference $E_{\mathrm{sw}}-E^{\circ}$, and reduction of protons as a possible source of anomalous results can, accordingly, be ruled out.

The conclusion resulting from all these experiments is that the two transient electroanalytical techniques, DPSC and DCV, do give different values of the apparent reaction order in $\mathrm{PhOH}$ under the experimental conditions of the study and we now demonstrate that this is partly caused by deviations from pseudo first-order conditions in the concentration ranges of this and the earlier studies.

As a starting point, it is pertinent to examine the similarities and differences between the two techniques in more detail. For this purpose, the potential-time and response characteristics are illustrated in Fig. 2. Common to both techniques is that the initial electrode process is reduction of $A$ to $A^{*}$, and the fraction of $A^{*}$ which survives the experimental conditions on the time scale of the experiment is monitored through the reverse process, oxidation of $\mathrm{A}^{\mp}$ back to $\mathrm{A}$. In a typical experiment, the response, $i$ during DPSC and $i^{\prime}=$ $\mathrm{d} i / \mathrm{d} t$ during $\mathrm{DCV}$, is measured at two values of the time, $t$, as indicated by the broken lines in
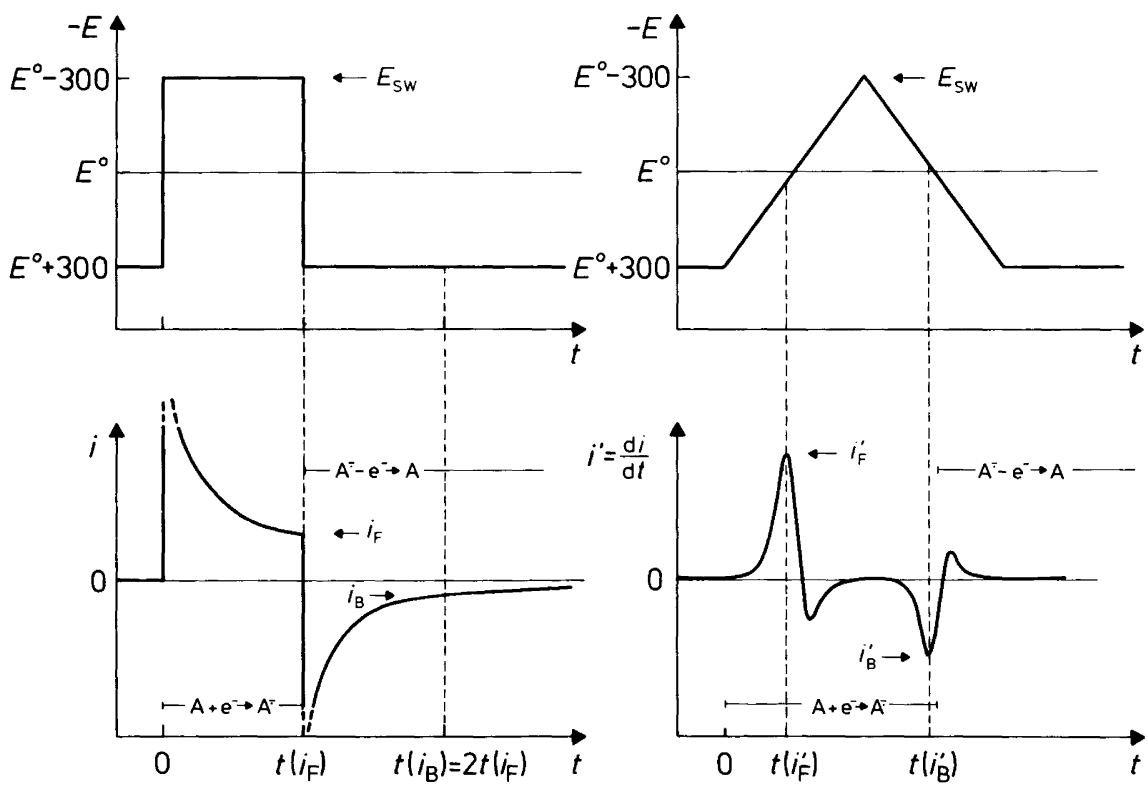

Fig. 2. Potential-time (top) and response-time (bottom) characteristics for DPSC (left) and DCV (right). 
Fig. 2, and the results are given as the ratios $R_{\mathrm{I}}=$ $-i_{\mathrm{B}} /\left(0.2929 i_{\mathrm{F}}\right)$ and $R_{\mathrm{I}}^{\prime}=-i_{\mathrm{B}}^{\prime} / i_{\mathrm{F}}^{\prime}$, which are the parameters used in the data analysis. A major difference between the two techniques is the nature of the electrode process in the time interval between these two measurements. During DPSC, the value of $E-E^{\circ}$ is positive, e.g. +300 $\mathrm{mV}$. Accordingly, the oxidation of $\mathrm{A}^{-}$to $\mathrm{A}$ takes place at a rate close to that for a diffusion-controlled process, whereas during $\mathrm{DCV}$, the value of $E-E^{\circ}$ is negative and, as a consequence, the reduction of $\mathrm{A}$ to $\mathrm{A}^{\bar{*}}$ continues to take place in this time interval. In other words, during DPSC, the original concentration conditions are being approached in the time interval between the two measurements, while during DCV, the perturbation of the concentration profiles, including that for $\mathrm{PhOH}$, is further accentuated. The extent to which this has consequences for the validity of the assumption of pseudo first-order conditions depends on the value of $C_{\mathrm{PhOH}}^{\circ} / C_{\mathrm{A}}^{\circ}$ and the relative time scale of the two techniques. The effect is most clearly demonstrated by an example:

Consider the reaction scheme (1)-(5) assuming that the formation of the $\mathrm{PhOH} / \mathrm{PhO}^{-}$complex (eqn. 5) can be regarded as an irreversible process. At $C_{\mathrm{PhOH}}^{\circ} / C_{\mathrm{A}}^{\circ}=6$, for example, the values of the parameters $k_{2} C_{\mathrm{PhOH}}^{\circ} \tau_{1 / 2}$ and $k_{2} C_{\mathrm{PhOH}}^{\circ} R T /\left(v_{1 / 2} n F\right)$

$\tau_{1 / 2}=0.1834 /\left(k_{2} C_{\mathrm{PhOH}}^{\mathrm{o}}\right)$

$v_{1 / 2}=k_{2} C_{\mathrm{PhOH}}^{\circ} R T /(0.1403 F)$

are equal to 0.1834 and 0.1403 (cf. Table 4), and the correspondence between $\tau_{1 / 2}$ or $v_{1 / 2}$ and $k_{2} C_{\mathrm{PhOH}}^{\circ}$ can then conveniently be expressed as eqns. (20) and (21). If we now assume that $k_{2}$ is equal to $5000 \mathrm{M}^{-1} \mathrm{~s}^{-1}$, which is close to the average of the published values, and that $C_{\mathrm{PhOH}}^{\circ}$ is equal to $6 \mathrm{mM}$, we arrive at the values $\tau_{1 / 2}=6.11$ ms and $v_{1 / 2}=5.50 \mathrm{~V} \cdot \mathrm{s}^{-1}$ for the pulse width and the potential sweep rate at $298 \mathrm{~K}$. The total time of the DPSC experiment is twice the value of $\tau_{1 / 2}$ which in the present case amounts to $12.22 \mathrm{~ms}$. Assuming now that the potential range during $\mathrm{DCV}$ is from $E-E^{\circ}=300 \mathrm{mV}$ to $E-E^{\circ}=-300$ $\mathrm{mV}$, the total scan is $1200 \mathrm{mV}$, which at a sweep rate of $5.50 \mathrm{~V} \cdot \mathrm{s}^{-1}$ results in a total DCV experiment time of $218 \mathrm{~ms}$, approximately 18 times that of the DPSC experiment.

In order to illustrate the difference in $\mathrm{PhOH}$ consumption for the two techniques due to this difference in time scale, we calculated the values of the additional charge consumed due to the occurrence of steps (2)-(5), $q-q_{\mathrm{rev}}$, at the times at which the measurements were taken. The parameter $q$ is the total charge and $q_{\mathrm{rev}}$ is the charge in the absence of the follow-up reactions, i.e. at $k_{2} C_{\mathrm{A}}^{\circ} R T /(v n F)=k_{2} C_{\mathrm{A}}^{\circ} \tau=0$. The results for three different degrees of conversion are summarized in Table 3. By comparison of the values at $R_{1}=R_{\mathrm{t}}^{\prime}$ $=0.5$, which were used in this work, it is noticed that the additional charges at the times of the first measurements, $\left(q-q_{\mathrm{rev}}\right)_{1}$, i.e. at $t=t\left(i_{\mathrm{F}}\right)=\tau_{1 / 2}$ (DPSC) and $t=t\left(i_{\mathrm{F}}^{\prime}\right)(\mathrm{DCV})$, are of similar magnitude, the values being 0.063 (DPSC) and 0.048 (DCV). However, this situation is changed dramatically when the comparison is made at the time of the second measurement, i.e. at $t=\left(i_{\mathrm{B}}\right)=$ $2 \tau_{1 / 2}$ (DPSC) and $t=t\left(i_{\mathrm{B}}^{\prime}\right)(\mathrm{DCV})$, at which the additional charge, $\left(q-q_{\mathrm{rev}}\right)_{2}$, for DCV, 2.395 , is approximately 12 times that for DPSC, 0.195. Since the magnitude of the additional charge is closely related to the consumption of $\mathrm{PhOH}$, the question now is whether the much higher conversion during $\mathrm{DCV}$ is sufficient to cause the value of $[\mathrm{PhOH}] / C_{\mathrm{A}}^{\circ}$ in the reaction layer to deviate appreciably from $C_{\mathrm{PhOH}}^{\circ} / C_{\mathrm{A}}^{\circ}$. The effect is illustrated in Fig. 3 which shows simulated concentration profiles for $\mathrm{A}, \mathrm{A}^{-}$and $\mathrm{PhOH}$ at $C_{\mathrm{PhOH}}^{\circ} / C_{\mathrm{A}}^{\circ}=6$ for

Table 3. Values of the normalized additional charge, $q-q_{\mathrm{rev}}$, for mechanism (1)-(5) at $C_{\mathrm{PhOH}}^{\circ} / C_{\mathrm{A}}^{\circ}=6$ for different degrees of conversion.

\begin{tabular}{|c|c|c|c|c|c|c|}
\hline & \multicolumn{3}{|c|}{$R_{1}$ (DPSC) } & \multicolumn{3}{|c|}{$R_{1}^{\prime}(\mathrm{DCV})$} \\
\hline & 0.3 & 0.5 & 0.8 & 0.3 & 0.5 & 0.8 \\
\hline $\begin{array}{l}\left(q-q_{\mathrm{rev}}\right)_{1}{ }^{a} \\
\left(q-q_{\mathrm{rev}}\right)_{2}{ }^{b}\end{array}$ & $\begin{array}{l}0.107 \\
0.318\end{array}$ & $\begin{array}{l}0.063 \\
0.195\end{array}$ & $\begin{array}{l}0.020 \\
0.066\end{array}$ & $\begin{array}{l}0.166 \\
3.868\end{array}$ & $\begin{array}{l}0.048 \\
2.395\end{array}$ & $\begin{array}{l}0.009 \\
0.852\end{array}$ \\
\hline
\end{tabular}

${ }^{a}$ At the time of the first measurement. ${ }^{b}$ At the time of the second measurement. 
DOUBLE POTENTIAL STEP CHRONOAMPEROMETRY

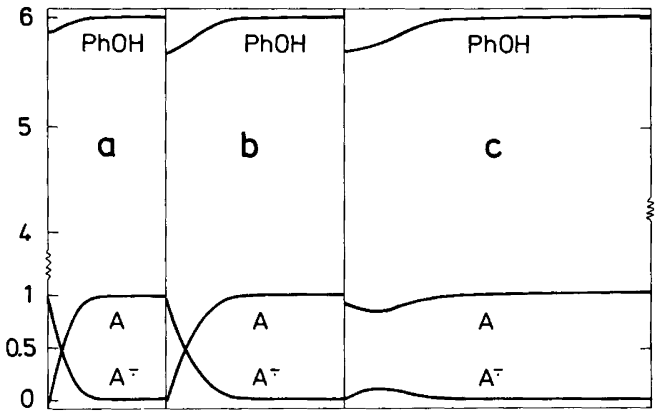

DERIVATIVE CYCLIC VOLTAMMETRY

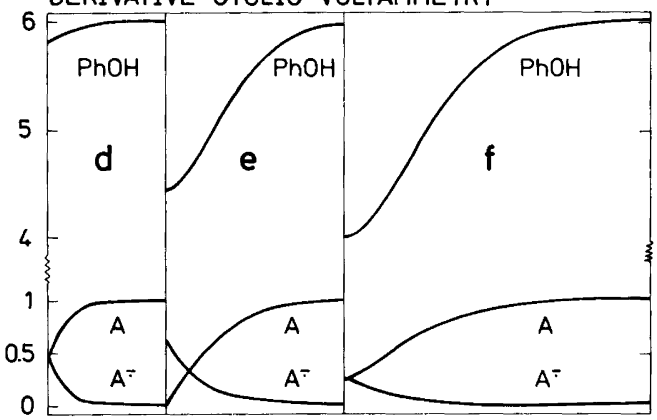

Distance from the electrode surface

Fig. 3. Concentration profiles for $\mathrm{A}, \mathrm{A}^{-}$and $\mathrm{PhOH}$ at $C_{\mathrm{PhOH}}^{\circ} / C_{\mathrm{A}}^{\circ}=6$ (mechanism 1-5). The numbers given at the $\mathrm{Y}$ axis represent values of $[\mathrm{A}] / C_{\mathrm{A}}^{\circ},\left[\mathrm{A}^{-}\right] / C_{\mathrm{A}}^{\circ}$ and $[\mathrm{PhOH}] / C_{\mathrm{A}}^{\circ}$, respectively. The profiles correspond to (a) $t=0.4 t_{\mathrm{F}}$, (b) $t=t_{\mathrm{F}}$, (c) $t=2 t_{\mathrm{F}}$, (d) $t=t\left(i_{\mathrm{F}}^{\prime}\right)$,

(e) $E=E_{\mathrm{sw}}$ and (f) $t=t\left(i_{\mathrm{B}}^{\prime}\right)$.

both techniques at $k_{2} C_{\mathrm{A}}^{\circ} \tau=0.03057$ (DPSC) and $k_{2} C_{\mathrm{A}}^{\circ} R T /(v n F)=0.02338(\mathrm{DCV})$ corresponding to $R_{\mathrm{I}}=R_{\mathrm{I}}^{\prime}=0.5$ (cf. Table 4). The minimum value of $[\mathrm{PhOH}] / C_{\mathrm{A}}^{\circ}$ during DPSC is observed at the end of the first potential step at $t=t\left(i_{\mathrm{F}}\right)=\tau_{1 / 2}$ (profile b) at which time the first current measurement is taken. The value amounts to 5.67 or $94.5 \%$ of $C_{\mathrm{PhOH}}^{\circ} / C_{\mathrm{A}}^{\circ}$. During the second potential step at which the back oxidation of $\mathrm{A}^{\bar{\gamma}}$ to A proceeds at the diffusion-controlled rate, thereby

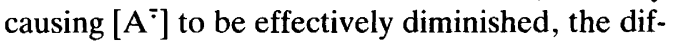
fusion of $\mathrm{PhOH}$ towards the electrode surface can now easily furnish the amount needed for the chemical reactions and consequently the value of $[\mathrm{PhOH}] / C_{\mathrm{A}}^{\circ}$ increases slightly in this time interval. At the time of the second current measurement, $t$ $=t\left(i_{\mathrm{B}}\right)=2 \tau_{1 / 2}$, the value of $[\mathrm{PhOH}] / C_{\mathrm{A}}^{\circ}$ is 5.70 (profile c), corresponding to $95 \%$ of $C_{\mathrm{PhOH}}^{\circ} / C_{\mathrm{A}}^{\circ}$. It is clearly seen that the deviations from pseudo first-order conditions are small during the complete DPSC experiment, even when $C_{\mathrm{PhOH}}^{\circ} / C_{\mathrm{A}}^{\circ}$ is as low as 6. The DCV profile for $\mathrm{PhOH}$ during the time until the first measurement is taken, close to $E=E^{\circ}$ in the forward scan (profile d), is essentially unperturbed, and in that respect resembles the corresponding DPSC profile as also expected from the values of the additional charge given in Table 3. However, this is not the case when the second measurement is taken close to $E$ $=E^{\circ}$ in the backward scan (profile f). Due to the continuous consumption of $\mathrm{PhOH}$ in the considerable time interval between the two measurements, the value of $[\mathrm{PhOH}] / \mathrm{C}_{\mathrm{A}}^{\circ}$ at the time of the second measurement is as low as 4.00 , or only $67 \%$ of $C_{\mathrm{PhOH}}^{\circ} / C_{\mathrm{A}}^{\circ}$, which is close to the minimum value during the DCV experiment. Another way of illustrating the magnitude of the $\mathrm{PhOH}$ consumption during DCV is comparison of the surface concentration of $\mathrm{PhOH}$ at the time of the second measurement with the bulk value after exhaustive reduction of $\mathrm{A}$ to $\mathrm{AH}_{2}$. The latter value is 2 for mechanism (1)-(5) at $C_{\mathrm{PhOH}}^{\circ} / C_{\mathrm{A}}^{\circ}=6$, or in other words, the surface concentration of $\mathrm{PhOH}$ is only twice this limiting value when the second DCV measurement is taken. Obviously, the reaction cannot be treated as a pseudo firstorder process during DCV at $C_{\mathrm{PhOH}}^{\circ} / C_{\mathrm{A}}^{\circ}=6$. However, the deviations from pseudo first-order conditions will be progressively less pronounced as the value of $C_{\mathrm{PhOH}}^{\circ} / C_{\mathrm{A}}^{\circ}$ increases, and the question now is to what extent this will be reflected in the apparent reaction orders measured in the concentration range of the experimental work.

To answer this question, we carried out an extensive series of digital simulations for the two techniques, again assuming that the reaction is adequately described by the scheme including steps (1) to (5) with (5) being irreversible. The results of the calculations were treated in a manner analogous to that described for the experimental data, i.e. as $\log \left[1 /\left(k C_{\mathrm{A}}^{\circ} \tau_{R_{\mathrm{I}}}\right)\right]$ or $\log \left[v_{R_{\mathrm{I}}} n F /\right.$ $\left.\left(k C_{\mathrm{A}}^{\circ} R T\right)\right]$ vs. $\log \left(C_{\mathrm{PhOH}}^{\circ} / C_{\mathrm{A}}^{\circ}\right)$. The results of this treatment at various degrees of conversion, i.e. at different values of $R_{\mathrm{I}}$ or $R_{\mathrm{I}}^{\prime}$, are depicted in Fig. 4 in the range $C_{\mathrm{PhOH}}^{\circ} / C_{\mathrm{A}}^{\circ}=6-100$. It should be recalled that plots of this kind are not expected to be linear according to theory, but when the concentration ratio is restricted to vary between 6 and 100 the deviations from linearity are small, as demonstrated by the data in Fig. 4, and the slope 


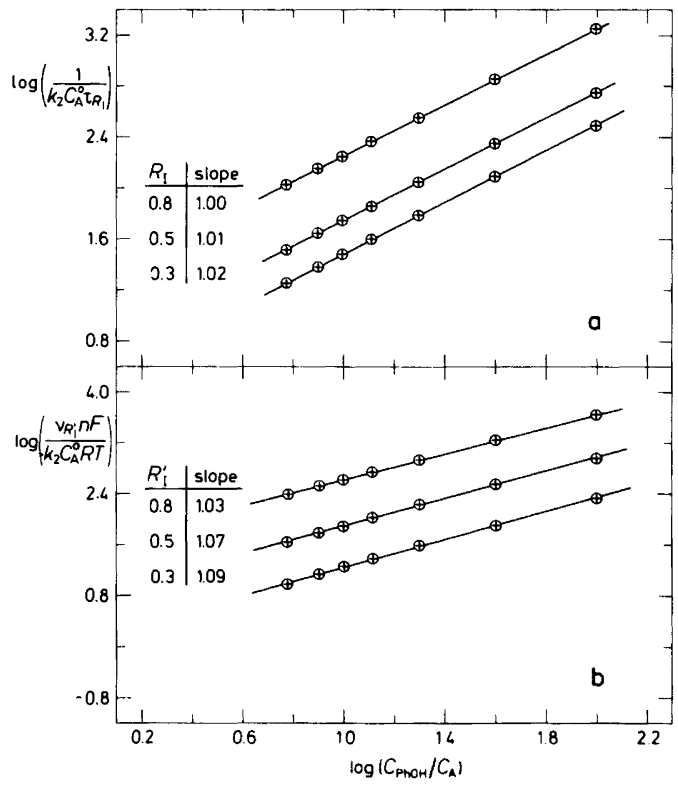

Fig. 4. Reaction order analysis by (a) DPSC and (b) DCV of theoretical data for mechanism (1)-(5) in the range $C_{\mathrm{PhOH}}^{\circ} / C_{\mathrm{A}}^{\circ}=6-100$. The slopes indicate the apparent reaction orders at the degree of conversion corresponding to the values of $R_{1}$ and $R_{1}^{\prime}$ given in the figure.

of the regression line defined by the points provides a convenient measure of the sensitivity of $\tau_{1 / 2}$ and $v_{1 / 2}$ to variations in the concentration ratio.

Two features of the plots are noteworthy. First, the apparent reaction orders increase with increasing conversion, and second, DPSC seems to be much less affected than DCV. Both these trends are in keeping with the data in Table 3 and the considerations made above and demonstrate that a process like mechanism (1)-(5), which is truly first-order with respect to $\mathrm{PhOH}$, may give rise to apparent DCV reaction orders significantly higher than unity in this species when data in the entire range $C_{\mathrm{PhOH}}^{\circ} / C_{\mathrm{A}}^{\circ}=6-100$ are included in the analysis. Obviously, the apparent reaction order will approach unity with increasing values of the lower limit of $C_{\mathrm{PhOH}}^{\circ} / C_{\mathrm{A}}^{\circ}$. If, for example, the concentration range is restricted to $C_{\mathrm{PhOH}}^{\circ} / C_{\mathrm{A}}^{\circ}$ $=10-100$, the apparent reaction order at $R_{\mathrm{I}}^{\prime}=0.5$ decreases from 1.07 to 1.05 .

Until now, we have only been concerned with the deviations from pseudo first-order conditions from a purely mechanistic point of view. Another important question is: by how much are the second-order rate constants, $k_{2}$, calculated without considering these deviations, in error? To answer this question, we have tabulated values of $k_{2} C_{\mathrm{A}}^{\circ} \tau_{1 / 2}$ and $\mathrm{k}_{2} C_{\mathrm{PhOH}}^{\circ} \tau_{1 / 2}$ (DPSC) as well as $k_{2} C_{\mathrm{A}}^{\circ} R T /\left(v_{1 / 2} n F\right)$ and $k_{2} C_{\mathrm{PhOH}}^{\circ} R T /\left(v_{12} n F\right)$ (DCV) in the range $C_{\mathrm{PhOH}}^{\circ} / C_{\mathrm{A}}^{\circ}=2-100$ in Table 4 . The basis for the calculations of the error in $k_{2}$ is the case for which $[\mathrm{PhOH}]=C_{\mathrm{PhOH}}^{\mathrm{o}}$, i.e. pseudo first-order conditions, a situation reached in principle only when the concentration ratio $C_{\mathrm{PhOH}}^{\mathrm{o}} / C_{\mathrm{A}}^{\circ}$ is infinitely large. In this limiting case, the observed pseudo first-order rate constant, $k_{2}^{\prime}$, is equal to $k_{2} C_{\mathrm{PhOH}}^{\circ}$. On moving from this hypothetical condition to experimentally accessible concentration ratios, the error in $k_{2}$ due to the deviations from pseudo first-order conditions obviously increases with decreasing values of $C_{\mathrm{PhOH}}^{\circ} / C_{\mathrm{A}}^{\circ}$. If a maximum error in $k_{2}$ of $5 \%$ is accepted, inspection of Table 4 shows that DPSC allows the concentration ratio to be as small as 5 , whereas the same precision calls for a value of $C_{\mathrm{PhOH}}^{\circ} / C_{\mathrm{A}}^{\circ}$ between 20 and 40 during DCV. At $C_{\mathrm{A}}^{\circ}=1 \mathrm{mM}$, which is typical during DCV mechanism analysis, this corresponds to a minimum value of $C_{\mathrm{PhOH}}^{\circ}$ of more than $20 \mathrm{mM}$. Since for other reasons, such as solvent effects and the risk of problems due to adsorption, the concentration of $\mathrm{PhOH}$ or other similar acids should not exceed $100 \mathrm{mM}$, the general conclusion is that incorporation of the concentration proportions in the analysis of experimental DCV data is necessary for accurate work.

The theoretical data presented so far have demonstrated that reaction scheme (1)-(5) with rate determining (2) and irreversible (5) in the concentration range $C_{\mathrm{PhOH}}^{\circ} / C_{\mathrm{A}}^{\circ}=6$ to 100 is predicted to result in the apparent reaction orders 1.01 (DPSC) and 1.07 (DCV) when the data are analyzed in terms of eqns. (17) and, (19) solely due to deviations from pseudo first-order conditions. Whereas the DPSC value certainly cannot be distinguished from unity within experimental error, a deviation amounting to 0.07 is expected to show up in careful DCV work. However, when the experimental values given in Table 1 are compared with the theoretical predictions in Fig. 4, it is obvious that effects other than deviations from pseudo first-order conditions contribute to the magnitude of the apparent reaction order. 
Table 4. The error introduced in the second-order rate constant, $k_{2}$, by assuming pseudo first-order conditions for mechanism (1)-(5). ${ }^{2}$

\begin{tabular}{|c|c|c|c|c|c|c|}
\hline \multirow[b]{2}{*}{$C_{\mathrm{PhOH}}^{\circ} / C_{\mathrm{A}}^{\circ}$} & \multicolumn{3}{|l|}{ DPSC } & \multicolumn{3}{|l|}{ DCV } \\
\hline & $k_{2} C_{A}^{\circ} \tau_{1 / 2}$ & $k_{2} C_{\mathrm{PhOH}}^{\circ} \tau_{1 / 2}$ & Error $(\%)^{b}$ & $k_{2} C_{\mathrm{A}}^{\circ} R T /\left(v_{1 / 2} n F\right)$ & $k_{2} C_{\mathrm{PhOH}}^{\circ} R T /\left(v_{1 / 2} n F\right)$ & Error $(\%)^{t}$ \\
\hline$\infty$ & 0 & $0.1768^{c}$ & 0 & 0 & $0.1116^{c}$ & 0 \\
\hline 100 & 0.00177 & 0.1770 & 0.1 & 0.00113 & 0.1130 & 1.3 \\
\hline 40 & 0.004443 & 0.1777 & 0.5 & 0.002875 & 0.1150 & 3.0 \\
\hline 20 & 0.008935 & 0.1787 & 1.1 & 0.005935 & 0.1187 & 6.4 \\
\hline 13 & 0.01383 & 0.1798 & 1.7 & 0.00946 & 0.1230 & 10.2 \\
\hline 10 & 0.01807 & 0.1807 & 2.2 & 0.01270 & 0.1270 & 13.8 \\
\hline 8 & 0.02272 & 0.1818 & 2.8 & 0.01644 & 0.1315 & 17.8 \\
\hline 6 & 0.03057 & 0.1834 & 3.7 & 0.02338 & 0.1403 & 25.7 \\
\hline 5 & 0.03698 & 0.1849 & 4.6 & 0.02960 & 0.1480 & 32.6 \\
\hline 4 & 0.04676 & 0.1870 & 5.8 & 0.04046 & 0.1618 & 45.0 \\
\hline 3 & 0.06363 & 0.1909 & 8.0 & 0.06422 & 0.1927 & 72.7 \\
\hline 2 & 0.09966 & 0.1993 & 12.7 & 0.1589 & 0.3178 & 185 \\
\hline
\end{tabular}

${ }^{a}$ The error for the mechanism including only steps (1)-(4) will amount to one-half of the values given above. ${ }^{\circ} \mathrm{C}$ alculated as the deviation from the pseudo first-order value. ${ }^{C}$ Pseudo first-order value.

Since our conditions involve semi-infinite linear diffusion as the only mode of mass transport, the effectiveness by which the $\mathrm{PhOH}$ consumed during the course of the reaction is replaced depends on the diffusion coefficient, $D_{\mathrm{PhOH}}$, such that decreasing values of $D_{\mathrm{PhOH}}$ will result in increasing deviations from pseudo first-order conditions. The simulations of the data presented in Fig. 3 were all carried out assuming that $D_{\mathrm{PhOH}}$ was equal to $D_{\mathrm{A}}$. However, it is well known that $\mathrm{PhOH}$ dissolved in polar aprotic solvents is strongly associated to the solvent molecules through hydrogen bonds. ${ }^{24,43-48}$ Because of this, it seems reasonable to assume that the diffusion coefficient for $\mathrm{PhOH}$ may, in fact, be smaller than that for anthracene, $D_{\mathrm{A}}$. It has been reported in a number of cases that the relative magnitude of the diffusion coefficients of species involved in electrochemical reactions may have a considerable effect on the related theoretical data. ${ }^{49-52}$ To the best of our knowledge, the value of $D_{\mathrm{PhOH}}$ has not been measured accurately under our experimental conditions; therefore, in order to get an estimate of the magnitude of the possible effect of the inequality of $D_{\mathrm{PhOH}}$ and $D_{\mathrm{A}}$, we have carried out a series of calculations in which the ratio $D_{\mathrm{A}} / D_{\mathrm{PhOH}}$ was varied between 1 and 45 . The results of these calculations in the form of apparent reaction orders are presented in Table 5. The trends in the data are again as expected. The apparent reaction order calculated from DCV data is indeed sensitive to variations in the diffusion coefficient ratio, while that based on DPSC is hardly affected at all. We had to consider four significant digits in order to observe any difference for the DPSC data which then were 1.012 at $D_{\mathrm{A}} / D_{\mathrm{PhOH}}=1$ and 1.014 at $D_{\mathrm{A}} / D_{\mathrm{PhOH}}=45$. However, the effect even during DCV is only moderate for reasonable $D_{\mathrm{A}} / D_{\mathrm{PhOH}}$ values and we conclude that differences in $D_{\mathrm{A}}$ and $D_{\mathrm{PhOH}}$ under the experimental conditions are of only minor im-

Table 5. The influence of the diffusion coefficient ratio, $D_{\mathrm{A}} / D_{\mathrm{PhOH}}$, on the apparent reaction order for mechanism (1)-(5). ${ }^{a}$

\begin{tabular}{cccc}
\hline & $\mathrm{DPSC}$ & & $\mathrm{DCV}$ \\
\cline { 2 - 3 }$D_{\mathrm{A}} / D_{\mathrm{PhOH}}$ & $\frac{\operatorname{dlog}\left[1 /\left(k_{2} C_{\mathrm{A}}^{\circ} \tau_{1 / 2}\right)\right]}{\operatorname{dlog}\left(C_{\mathrm{PhOH}}^{\circ} / C_{\mathrm{A}}^{\circ}\right)}$ & & $\frac{\operatorname{dlog}\left[v_{1 / 2} n F /\left(k_{2} C_{\mathrm{A}}^{\circ} R T\right)\right]}{\operatorname{dlog}\left(C_{\mathrm{PhOH}}^{\circ} / C_{\mathrm{A}}^{\circ}\right)}$ \\
\hline & 1.01 & \\
4.0 & 1.01 & 1.07 \\
4.5 & 1.01 & 1.11 \\
45 & 1.01 & 1.13 \\
\hline
\end{tabular}

${ }^{a}$ Concentration range: $C_{\mathrm{PhOH}}^{\circ} / C_{\mathrm{A}}^{\circ}=6-100$. 
portance for the magnitude of the apparent reaction order, and may in general be neglected.

Another possible source of the difference between the theoretical and experimental data may be found in the neglect of the equilibrium between $\mathrm{PhOH}$ and the corresponding dimer (eqn. 22), which is expected to be a much stronger acid than $\mathrm{PhOH}$, partly due to the large value of $K_{5}$. Unfortunately, the value of $K_{22}$ in DMF appears not to be known. However, for $\mathrm{CCl}_{4}$ a value of 0.74 has been reported ${ }^{53}$ which seems to indicate that $K_{22}$ may have a significant value in DMF.

$$
2 \mathrm{PhOH} \stackrel{K_{22}}{\rightleftharpoons}(\mathrm{PhOH})_{2}
$$

The possible role of $(\mathrm{PhOH})_{2}$ in the reaction scheme for protonation of anion radicals derived from alternant aromatic hydrocarbons and related species is presently under investigation in order to improve the understanding of these and other related proton-transfer reactions in polar aprotic solvents.

It is evident from these results and the discussion given in the previous paragraphs that the deviation from pseudo first-order conditions cannot be neglected during DCV at low values of $C_{\mathrm{PhOH}}^{\circ} / C_{\mathrm{A}}^{\circ}$. As a consequence of this, we have extended our studies to include measurements in the range $C_{\mathrm{PhOH}}^{\circ} / C_{\mathrm{A}}^{\circ}=1-2$ at $C_{\mathrm{A}}^{\circ}=1-2 \mathrm{mM}$, one advantage being that the response is expected to reflect clearly the magnitude of the stoichiometric contributions from equilibrium (5). Furthermore, kinetic complications due to the participation of $(\mathrm{PhOH})_{2}$ as a proton source are expected to be less pronounced at low values of $C_{\mathrm{PhOH}}^{\circ}$. Working curves at different values of $C_{\mathrm{PhOH}}^{\circ} / C_{\mathrm{A}}^{\circ}$ are shown in Fig. 5 (DPSC) and Fig. 6 (DCV). Curves which correspond to truly pseudo firstorder conditions are included for comparison $(\infty)$. Once again it is evident that DPSC shows very little sensitivity to variation in the ratio $C_{\mathrm{PhOH}}^{\circ} / C_{\mathrm{A}}^{\circ}$, whereas the DCV working curves differ considerably. It is quite obvious that the differences between the DPSC working curves are too small to be of mechanistic significance, but this is not the case for DCV, and this expected sensitivity to the relative amount of $\mathrm{PhOH}$ and $\mathrm{A}$ was used to test experimentally the assumption that the formation of the $\mathrm{PhOH} / \mathrm{PhO}^{-}$complex may indeed be regarded as an irreversible pro-

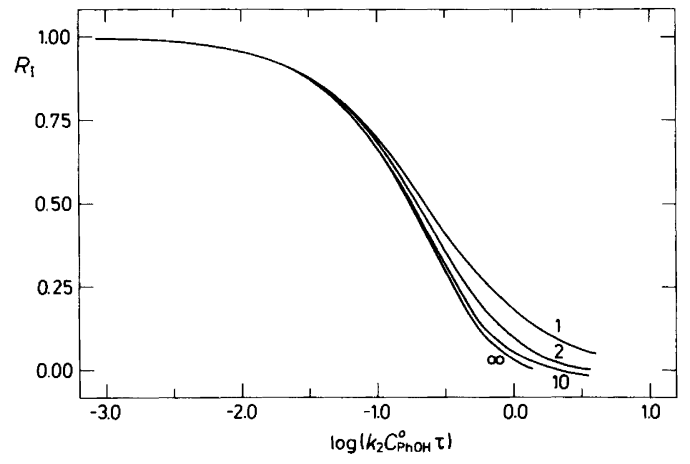

Fig. 5. Double potential step chronoamperometry working curves for mechanism (1)-(5) at $C_{\mathrm{PhOH}}^{\circ} / C_{\mathrm{A}}^{\circ}$ $=1,2,10$ and $\infty$.

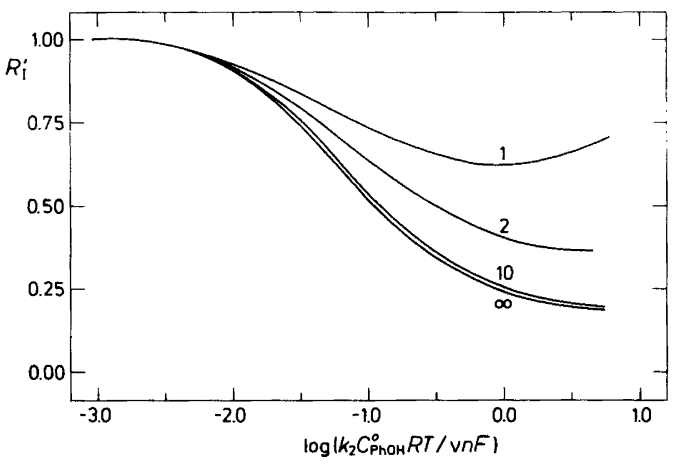

Fig. 6. Derivative cyclic voltammetry working curves for mechanism (1)-(5) at $C_{\mathrm{PhOH}}^{\circ} / C_{\mathrm{A}}^{\circ}=1,2,10$ and $\infty$.

cess which only affects the overall stoichiometry of the process.

Working curves were calculated for three different mechanisms: (a) the conventional mechanism in which the $\mathrm{PhO}^{-}$ions formed during the course of the reaction were assumed to exist as free ions, (b) the $\mathrm{PhOH} / \mathrm{PhO}^{-}$complex mechanism, i.e. steps (1)-(4) plus irreversible (5) and (c) a mechanism including steps (1)-(4), and a fifth step corresponding to the irreversible formation of a $2 \mathrm{PhOH} / \mathrm{PhO}^{-}$complex (eqn. 23). Com-

$$
2 \mathrm{PhOH}+\mathrm{PhO}^{-} \stackrel{K_{23}}{\rightleftharpoons} \underset{\left(K_{23} \gg 1\right)}{2 \mathrm{PhOH} / \mathrm{PhO}^{-}}
$$

plexes between $\mathrm{ArOH}$ and $\mathrm{ArO}^{-}$with the composition $2 / 1$ have been observed in solution in a 


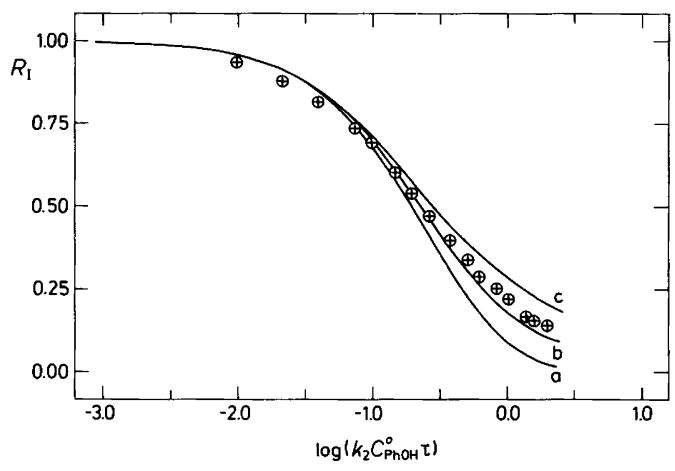

Fig. 7. Double potential step chronoamperometry working curves for (a) mechanism (1)-(4), (b) mechanism (1)-(5) and (c) mechanism (1)-(4), (23) at $C_{\mathrm{PhOH}}^{\circ} / C_{\mathrm{A}}^{\circ}=1$ together with experimental points obtained at $C_{\mathrm{PhOH}}^{\circ}=C_{\mathrm{A}}^{\circ}=2 \mathrm{mM}$ and $T=295 \mathrm{~K}$.

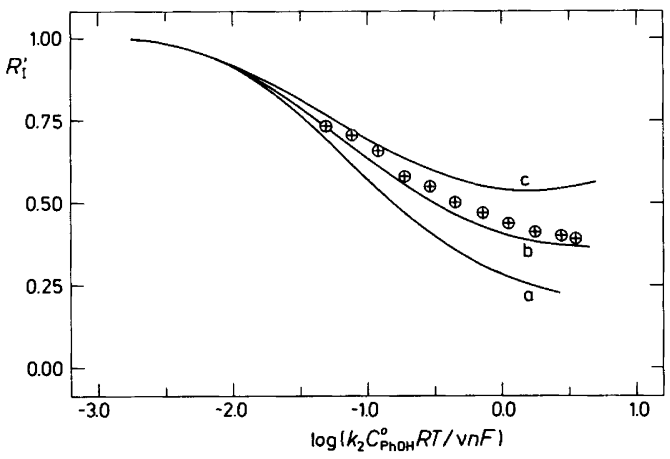

Fig. 8. Derivative cyclic voltammetry working curves for (a) mechanism (1)-(4), (b) mechanism (1)-(5) and (c) mechanism (1)-(4), (23) at $C_{\mathrm{PhOH}}^{\circ} / C_{\mathrm{A}}^{\circ}=2$ together with experimental points $(\oplus)$ obtained at $C_{\mathrm{PhOH}}^{\circ}$ $=4 \mathrm{mM}, C_{\mathrm{A}}^{\circ}=2 \mathrm{mM}$ and $T=295 \mathrm{~K}$.

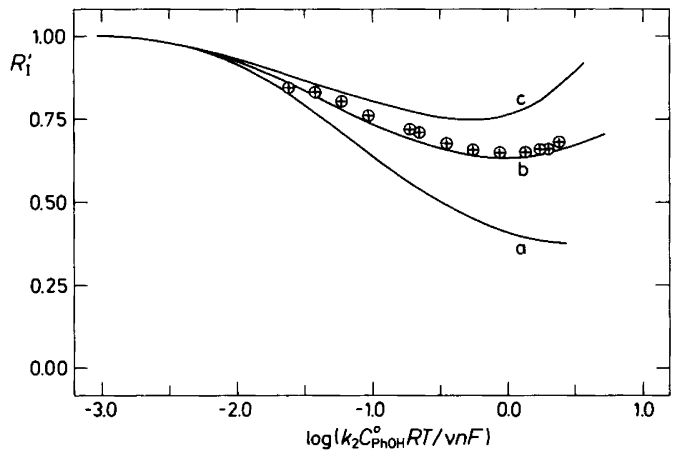

Fig. 9. Derivative cyclic voltammetry working curves for (a) mechanism (1)-(4), (b) mechanism (1)-(5) and (c) mechanism (1)-(4), (23) at $C_{\mathrm{PhOH}}^{\circ} / C_{\mathrm{A}}^{\circ}=1$ together with experimental points $(\oplus)$ obtained at $C_{\mathrm{PhOH}}^{\circ}=C_{\mathrm{A}}^{\circ}$ $=2 \mathrm{mM}$ and $T=295 \mathrm{~K}$. number of cases ${ }^{25,26,54}$ (and even 3/1 and 4/1 in the solid state) ${ }^{55,56}$ and might be expected to play a role under the present experimental conditions as well. The theoretical data for DPSC at $C_{\mathrm{PhOH}}^{\circ} / C_{\mathrm{A}}^{\circ}$ $=1$ are shown in Fig. 7 and for DCV at $C_{\mathrm{PhOH}}^{\circ} / C_{\mathrm{A}}^{\circ}$ $=2$ and 1 in Figs. 8 and 9, respectively. Included in the figures are experimental points at these concentration ratios and it is seen that the working curves for mechanism (1)-(5) are followed closely in all cases. This shows that reaction (5) may indeed be regarded as an irreversible process and that protonation of $\mathrm{A}^{-}$by $\mathrm{PhOH} / \mathrm{PhO}^{-}$ does not interfere kinetically in the time scale of DCV under the experimental conditions.

\section{Conclusions}

The work presented here serves to remove the remaining ambiguities in the mechanistic discussions of the reaction of anthracene anion radical with phenol. The differences in apparent reaction orders in phenol measured by DCV and DPSC originate partly in the deviations from pseudo first-order conditions which are accentuated in the DCV response to a much greater extent than in the DPSC data. We have shown that this difference in the two techniques arises as a consequence of the much higher degree of conversion of reactants under typical DCV conditions than during DPSC studies.

The greater sensitivity of DCV to stoichiometric conditions was taken advantage of to show the effect of phenol removal by phenoxide ion (reaction 5) by studying the reaction under purely second-order conditions, i.e. $C_{\mathrm{PhOH}}^{\mathrm{o}} / C_{\mathrm{A}}^{\circ}$ in the 1-2 range. A good correlation between experimental and theoretical data for mechanism (1)-(5) was found. These observations suggest that extension of concentration ratios from the usual pseudo first-order range to second-order conditions should find general applicability in related studies, and provide more detailed mechanistic information in many cases.

\section{Experimental}

Digital simulations were carried out on an HP 9826A desk computer essentially as described earlier. ${ }^{23}$ For DCV, the simulation sweep rate was $0.5 \mathrm{mV} /$ time step and differentiation was carried out by application of the least-squares procedure of Savitzky and Golay. ${ }^{57}$ For DPSC, the 
simulations involved 1000 time steps in each potential pulse. The instrumentation, data acquisition techniques, and the solvent and supporting electrolyte purification procedures were the same as described previously. ${ }^{23.58}$

Acknowledgments. We are grateful to the Carlsberg Foundation and The Danish Natural Science Research Council for grants to purchase the electrochemical instrumentation, and to the Carlsberg Foundation for support to M.F.N.

\section{References}

1. Todres, Z. V. Tetrahedron 41 (1985) 2771.

2. Juillard, M. and Chanon, M. Chem. Rev. 83 (1983) 425.

3. Symposia-in-print on Electron-Transfer Initiated Reactions. Tetrahedron 38 (1982) 1025.

4. Ashby, E. C. Pure Appl. Chem. 52 (1980) 545.

5. Rossi, R. A. and Rossi. R. H. ACS Monograph 178 (1983).

6. Holy, N. L. Chem. Rev. 74 (1974) 243.

7. Eberson, L. Adv. Phys. Org. Chem. 18(1982) 79.

8. Shono, T. Electroorganic Chemistry as a New Tool in Organic Synthesis, Springer, Berlin 1984.

9. Reichardt, C. Solvent Effects in Organic Chemistry, Verlag Chemie, Weinheim 1979.

10. Bank, S. and Bockrath, B. J. Am. Chem. Soc. 94 (1972) 6076.

11. Rainis, A., Tung, R. and Szwarc, M. J. Am. Chem. Soc. 95 (1973) 659.

12. Rainis, A., Tung, R. and Szwarc, M. Proc. R. Soc. London A339 (1974) 417.

13. Minnich, E. R., Long, L. D., Ceraso, J. M. and Dye, J. L. J. Am. Chem. Soc. 95 (1973) 1061.

14. Garst, J. F. and Pacifici, J. A. J. Am. Chem. Soc. 97 (1975) 1802.

15. Amatore, C. and Savéant, J. M. J. Electroanal. Chem. 107 (1980) 353.

16. Aalstad, B. and Parker, V. D. J. Electroanal. Chem. 112 (1980) 163.

17. Ahlberg, E. and Parker, V. D. J. Electroanal. Chem. 121 (1981) 73.

18. Ahlberg, E. and Parker, V. D. Acta Chem. Scand. Ser. B35 (1981) 117.

19. Parker, V. D. Acta Chem. Scand., Ser. B 35 (1981) 349.

20. Parker, V. D. Acta Chem. Scand., Ser. B 35 (1981) 373.

21. Amatore, C., Gareil, M. and Savéant, J. M. J. Electroanal. Chem. 147 (1983) 1.

22. Amatore, C., Gareil, M. and Savéant, J. M. J. Electroanal. Chem. 176 (1984) 377.
23. Nielsen, M. F., Hammerich, O. and Parker, V. D. Acta Chem. Scand., Ser., B 40 (1986) 101.

24. Bordwell, F. G., McCallum, R. J. and Olmstead, W. N. J. Org. Chem. 49 (1984) 1424.

25. Süttinger, R. and Strohbusch, F. Ber. Bunsenges. Phys. Chem. 88 (1984) 744.

26. Süttinger, R. and Strohbusch, F. Ber. Bunsenges. Phys. Chem. 88 (1984) 750.

27. Pawlak, Z., Magoński, J. and Strohbusch, F. J. Chem. Soc., Faraday Trans. 1, 81 (1985) 2021.

28. Kolthoff, I. M., Chantooni, M. K., Jr. and Bhowmik, S. J. Am. Chem. Soc. 90 (1968) 23.

29. Bordwell, F. G., Branca, J. C., Hughes, D. L. and Olmstead, W. N. J. Org. Chem. 45 (1980) 3305.

30. Bykova, L. N. and Petrov, S. I. Russ. Chem. Rev. 41 (1972) 975.

31. Hawley, M. D. and Feldberg, S. W. J. Phys. Chem. 70 (1966) 3459.

32. Mastragostino, M., Nadjo, L. and Savéant, J. M. Electrochim. Acta 13 (1968) 721.

33. Nadjo, L. and Savéant, J. M. J. Electroanal. Chem. 48 (1973) 113.

34. Parker. V. D. Acta. (hem. Scand., Ser. B.35 (1981) 259.

35. Parker, V. D. Acta. Chem. Scand., Ser. B 35 (1981) 373.

36. Parker, V. D. Acta. Chem. Scand., Ser. B 35 (1981) 233.

37. Parker, V. D. Acta. Chem. Scand., Ser. B 38 (1984) 165.

38. Parker, V. D. Acta. Chem. Scand., Ser. B 38 (1984) 243.

39. Feldberg, S. W. Electroanal. Chem. 3 (1969) 199.

40. Britz, D. Digital Simulation in Electrochemistry, Springer, Berlin 1981.

41. Feldberg, S. W. and Auerbach, C. Anal. Chem. 36 (1964) 505.

42. Flanagan, J. B. and Marcoux, L. J. Phys. Chem. 77 (1973) 1051.

43. Jawed, I. Bull. Chem. Soc. Jpn. 50 (1977) 2602.

44. Gramstad, T. and Sandström, J. Spectrochim. Acta $25 A$ (1969) 31.

45. Gramstad, T. and Fuglevik, W. J. Acta Chem. Scand. 16 (1962) 1369.

46. Austerheim, A. and Gramstad, T. Acta Chem. Scand., Ser. B39 (1985) 583.

47. Ruostesuo, P. Finn. Chem. Lett. (1978) 202.

48. Barry, J. E., Finkelstein, M. and Ross, S. D. J. Org. Chem. 49 (1984) 1669.

49. Andrieux, C. P., Hapiot, P. and Savéant, J. M. J. Electroanal. Chem. 172 (1984) 49.

50. Amatore, C., Garreau, D., Hammi, M., Pinson, J. and Savéant, J.M. J. Electroanal. Chem. 184 (1985) 1

51. Andrieux, C. P., Hapiot, P. and Savéant, J. M. J. Electroanal. Chem. 186 (1985) 237. 
52. Andrieux, C. P., Hapiot, P. and Savéant, J. M. J. Electroanal. Chem. 189 (1985) 121.

53. Maguire, M. M. and West, R. Spectrochim. Acta 17 (1961) 369.

54. Johansson, P.-A. Acta Pharm. Suec. 14 (1977) 345.

55. Hanson, A. W., McCulloch, A. W. and McInnes, A. G. Tetrahedron Lett. 23 (1982) 607.

56. Khan, M. A., McCulloch, A.W. and McInnes, A. G. Can. J. Chem. 63 (1985) 2119.
57. Savitzky, A. and Golay, M. Anal. Chem. 36 (1964) 1627.

58. Ahlberg, E. and Parker, V. D. Acta Chem. Scand., Ser. B 34 (1980) 97.

Received August 5, 1986. 